\title{
The Qualitative Difference in Information Systems Research and Practice
}

\author{
M. L. Markus \\ The Claremont Graduate School \\ Claremont, California 91711-6190 USA \\ Tel: (909) 607-3151 \\ FAX: (909) 621-8564 \\ E-mail: markusm@cgs.edu
}

\begin{abstract}
Since the Manchester conference on research methods in Information Systems (IS) more than ten years ago, qualitative IS researchers have made great strides toward acceptance both within the IS field and in broader academic communities. This is a major collective achievement of which we all should be proud. Yet, we may well have reached the point of diminishing returns in this direction. While incremental improvement is possible and desirable, many of us are motivated by more ambitious goals. Therefore, I invite you to join me in undertaking three ambitious ventures: celebrating diversity in qualitative methods, converging on content in our field, and pursuing practicality in IS research. These complementary activities are worthy in their own right and promise important instrumental benefits to our community of research practice.
\end{abstract}

In discussing what he would like to see me do in this address, Allen Lee asked me to conduct a grand tour of how well qualitative IS research has progressed since the Manchester and Copenhagen meetings and, also, what remains to be done. To me, "grand tour" conveys two rather contradictory images: leisurely strolls among the ruins of former civilizations and blitzkreig bus trips of crowded tourist traps. 
Neither of these images suits my current perspective on qualitative research in the IS field. Instead, I prefer the image of the newspaper sports page - online, if you prefer. I'm not a great sports fan, but the metaphor seems more apt than that of a grand tour. On the sports page, the past is largely forgotten except for epic victories and defeats, but yesterday's game and future contests are thoroughly critiqued.

\section{THE SCORE}

In this vein, I will spend little time paying homage to the past. I will single out few significant papers, methodological contributions, or heroic researchers. We have them, and I honor them. But what matters most to me now is how our record adds up and the contests we will enter in the future.

\subsection{Past Wins}

As I look back over the proceedings of the Manchester and Copenhagen meetings and the research published in IS over the same time frame, it is clear to me that qualitative research has won at least one major championship - academic acceptance, both within the IS field and within the larger domain of academic management studies. Today, most high-status members of the IS community acknowledge that qualitative research methods occupy an important niche along with formal modeling and quantitative empirical methods (survey and experiments). Qualitative studies and methodological essays dealing with qualitative methods increasingly appear in our conferences and journals. Some research articles employing qualitative methods figure among the seminal studies read by IS doctoral students. An increasing number of IS doctoral programs teach qualitative research methods and legitimize use of qualitative methods in dissertation research. Further, members of our field whose work is largely or exclusively qualitative in method have been granted promotion and tenure in their respective institutions, signifying that academics from other management disciplines also accept the legitimacy of qualitative IS research. Members of our field have been appointed to the editorial boards of journals in other fields. Other signs of acceptance can be noted.

As those of us who have been in the IS field for more than ten years know, achieving academic acceptance for qualitative research methods was no small feat. Winning this collective championship involved the deployment of at least three distinct talents. One was persuasion. Some of our heroes organized awareness building sessions at conferences and wrote book chapters and articles about qualitative methods. These activities exposed everyone in our field to qualitative research methods and made an increasingly persuasive case for the legitimacy of these methods in IS championship events, like promotion decisions and selection of papers for publication in " $\mathrm{A}$ " journals. A second contribution was demonstration. Others of our former and current stars showed through published accounts that qualitative empirical work produces 
valuable insights and explanations of IS phenomena and contributes to the development of theory. We each have our own favorite exemplars of qualitative IS research. A third contribution was elucidation. Champions in this last area studied the process of qualitative research and identified the elements that constitute or contribute to rigor. This type of contribution has enabled us to evaluate, improve, and teach qualitative research to others in various professional settings (e.g., research supervision and reviewing).

As in every recognized sport, qualitative IS research has its own Hall of Fame. At the same time, the role of the sport in the larger society -its functions of occupation, entertainment, and inspiration -is a collective achievement, not merely a function of its stars. Therefore, while I honor our heroes, I hope you will forgive me for not singling you out and dwelling on your triumphs. Instead, I would like us all to appreciate the magnitude of our collective achievement. And I would you to join me in planning our next championship events.

\subsection{Future Contests}

As I see it, we have gone just about as far as we can in the game we have been playing. We have achieved academic acceptance; what more can we expect to win in this arena? It seems unlikely to me that qualitative research will ever be accepted as inherently superior to formal and quantitative research methods, either in IS or in academic management research more broadly. Further, it does not even seem desirable to me that we should choose this ambition as our goal. After all, many wellregarded modern philosophers of science argue persuasively that there is no scientific basis for claiming the superiority of any scientific research method. While we should, I believe, continuously strive to improve our methods and thereby maintain our legitimacy, our future big victories must lie elsewhere.

I believe that we qualitative IS researchers have a unique opportunity to exhibit leadership in three important and related new contests. These new arenas are the celebration of diversity in qualitative research, convergence on content in our field, and the appreciation of practicality in IS research. For each, I will say what it is and why I think it is important.

\section{THE CELEBRATION OF DIVERSITY IN QUALITATIVE RESEARCH}

As you know, one of John van Manaan's books on methods is entitled Varieties [plural] of Qualitative Research (Van Manaan, Dabbs and Faulkner 1982). At the same time, I' $m$ aware, as I' $m$ sure you are, of several other books with very similar titles (Strauss and Corbin 1990; Miles and Huberman 1994) that nevertheless address only one of many possible varieties of qualitative research - different in each case. 
This casual observation symbolizes for me a part of our game that needs radical improvement.

At one level, those of us who specialize in qualitative research know that there are qualitatively different types of qualitative research in terms of philosophy, technique, and output. Consider the fact that the organizers of this conference commissioned survey papers on four different methods:

- the case study strategy,

- ethnography,

- action research, and

- critical social theory.

To this list one could add grounded theory development, hermeneutic interpretation and phenomenological inquiry, among others. In addition, many researchers use qualitative data collection and analysis techniques in conjunction with other types of rigorous and legitimate academic inquiry (e.g., surveys, formal or qualitative theoretical essays).

At another level, it is my observation that the differences among these methods are neither widely understood by our non-qualitative research colleagues nor truly respected by us. I have experienced, and I know that others in this room have experienced, reviews from qualitative research colleagues with the criticism that the right qualitative research philosophy or method has not been used. For instance, in his introduction to the proceedings of this conference, Allen Lee reported the comment of one author who felt that she should not have to apologize for being a positivist.

This troubles me deeply. It is an indication to me that we do not practice what we preach. When we argue for the legitimacy of qualitative research relative to formal and quantitative empirical methods, we claim that no method is inherently superior to any other. But when we review the research of qualitative research colleagues, we "diss"' those who do not do qualitative research exactly as we do. To me, this is pure and simple prejudice and an indication that we have turned a scientific technique into a religion.

I think of research methods as analogous to languages, artistic media, and technologies. Yes, there are, alas, wars over language, as over religion, but does this make any one language right? With my culturally diverse doctoral students, it is easy to explain the value of learning different methods in terms of learning different languages: Some languages can express concepts that will not translate into others. Learning new languages gives us new windows on the world.

Art provides another useful analogy with research methods. Newer media, like acrylics, photography, and performance art, may take years to become accepted as "artistic" and may never achieve true parity in perceived "artistic merit" with established media like oils. Nevertheless, only a reverse snob would call the new media

\footnotetext{
1"Diss" is ebonic for "disrespect."
} 
superior. They are simply different, offering unique and valuable ways of representing creative vision.

For this audience, the most compelling analogy should be between research methods and technology. From our own collective body of IS research, we know the dual enabling and constraining nature of technology. While technology helps us do some things better than we could do without it, it can also prevent us from doing other things. For those, we need different tools. Similarly, one research method can answer certain kinds of questions that others can't answer quite as well, but they also prevent us from asking questions that our methods can't answer. That is, in part, why I think we should all learn more than one method. And, if we who claim to understand qualitative research argue that there is only one right way to do it, we are deliberately blinding ourselves to many interesting and important research questions and phenomena.

I'm certainly not saying that "anything goes" in qualitative research, any more than I would say that anything goes in an experiment. When someone claims to have used the case study research strategy, I believe that we are all well within our rights (and obligations) as supervisors and reviewers to demand that the researcher apply the method rigorously as documented by the experts in that method. Significant deviations from the documented approach of a particular method require careful justification. On the other hand, we should never forget that new research problems may necessitate methodological innovations. (For scientific rigor, the features of innovative methods should be methodically justified in theoretical or empirical terms.)

The potential consequences of religious fervor (as opposed to scientific rigor) in the area of research methods are extremely negative. First, religious fervor stifles innovation. Second, it promotes unproductive conflicts and bad feelings within our relatively small community of researchers. Life is too short for this. Third, by failing to accept, or better yet, to celebrate the diversity among us, we unnecessarily risk our future evolutionary development. While life is short, extinction is eternal. Fourth, petty rivalries within our ranks distract us from fun and challenging opportunities to make positive contributions to the world at large.

\section{CONVERGENCE ON CONTENT}

Convergence on content is a second new contest which I propose that we as qualitative IS researchers should enter. By this I mean a concerted coming together of the disparate, even divisive, substantive factions in our field.

In the last few years I have heard many of our colleagues around the world express concerns about the signs of fragmentation in our field. One bit of evidence, frequently cited, is the emergence of small specialized conferences, such as WITS and 
WISE$^{2}$, that entice some of us away from meetings intended to represent the larger community, such as ICIS or AIS ${ }^{3}$. WITS and WISE are scheduled to precede ICIS and so, in theory, do not directly compete with ICIS for attendance. However, I am told that some attendees in these specialized meetings do not attend ICIS, claiming that it has much less value for them. To my mind, this suggests that some of the institutions intended to represent our entire field have ironically become too specialized to do so. They have, in essence, evolved into internally homogeneous factions, not unlike the new groups that hoist their own flags.

Some of you will undoubtedly see these as natural events or even as positive developments. In most living systems, differentiation increases with size. In human systems, involvement and commitment tend to decrease with size. Therefore, the emergence of small, internally homogeneous subfields can be viewed both as an inevitable result of our success as a academic field and as an essential development for the well being of our members.

However, I am deeply concerned that our field may be, not merely differentiating, but splitting into disconnected parts. If so, the trend is neither inevitable nor desirable. In my view, the splintering of our field would be a tragic loss. If the schisms just involved methodological differences, they would be bad enough, for reasons I argued earlier. However, because methods limit what can be learned as well as enabling important other learning, the splitting also involves ideas and research content. Intellectual compartmentalization poses serious threats to any academic field, by reducing the stimulus for creative innovation and growth.

Right now, three broad subfields in IS are in danger of growing apart. One group consists of researchers who mainly employ economic methods to address macro-level issues in IT use, management, and impacts. A second group predominantly uses engineering approaches to IT design and development. A third group uses noneconomic behavioral and social science methods (both quantitative and qualitative) to address mainly the micro-level problems associated with IS development and use. The diversity of content addressed within the IS field should be a great strength. But the splintering of our community could make diversity a great weakness, by cutting us off from each others' thinking and increasing the divisiveness among methodsbased factions.

Let me discuss one area in particular where fragmentation in our field seems already to be having negative consequences. Many of the behavioral science IS articles I have read recently, regardless of whether they are quantitative or qualitative in method, have almost totally ignored technological details - the features, if you will

${ }^{2}$ WITS is the Workshop on Information Technology and Systems; WISE is the Workshop on Information Systems Economics.

${ }^{3}$ ICIS is the International Conference on Information Systems; AIS is the Association for Information Systems. 
- of the information technology used in the studied settings. Why does this neglect of technology in behavioral IS research happen? Is it because technology is like the air we breathe, so pervasive that we hardly notice it? Is it because our focus on academic respectability and methodological excellence has distracted us from the substance of our field? Is it because we collectively reject materialism and embrace social construction, so that we "know" that technology itself does not matter?

Whatever the reason, the negative consequences are clear: Neither we nor others who read our work learn much about how variations in technology features shape human behavior. Further, we close ourselves off to opportunities to influence, and to learn from, other researchers and practitioners for whom technology details are the most interesting (if not the only important) aspect of IT. Finally, we unnecessarily expose ourselves to invidious comparisons with researchers in other fields (e.g., psychology and sociology) who are increasingly interested in IT. Put differently, I believe that we as members of the IS field have absolutely no comparative advantage in the study of behavioral issues related to IT unless we can draw handsomely upon a unique understanding of technological matters that elude most people in other fields. ${ }^{4}$

An example from the $\mathrm{CSCW}^{5}$ field of the type of qualitative research I would like to read more frequently in IS involves a study of electronic calendaring systems. Grudin and a colleague studied user behavior around two different calendar programs and found that social practices varied with system defaults (Grudin and Palen 1995). I can think of only a few examples of behavioral IS research that exhibit a similar level of technological detail. Yet, a growing body of research (much of it done by people outside IS) suggests that technological details matter (Griffith and Northcraft 1994).

In my view, lack of technological detail in behavioral IS research is a sad reflection of harmful content divergence in our field. Yet, it's one thing for me to advocate our pulling together, and quite another when we starting talking about who should take the first step. I argue that the first step should be taken by those of us who study the social and behavioral issues in IS. I think that we have more to gain by joining our technologically (and economically) oriented colleagues than they have from joining us; conversely, we also have more to lose intellectually and politically from content divergence than they do. Further, I believe it is possible for us to move toward these colleagues without losing the perspectives, methods, and skills that make us special. As evidence, I cite the CSCW meetings, which exhibit high tolerance for both engineering and social scientific perspectives. At those conferences, the juxtaposition of different approaches has usually generated more innovation and excitement than it has fields.

${ }^{4}$ Individually, of course, some of us may compete quite successfully with members of other

${ }^{5}$ Computer-supported cooperative work. 
conflict. In short, I am arguing that greater content convergence in our field (maintaining diversity of method) is a contest for us qualitative IS researchers to enter and play to win. The payoffs of even a modest success will include accumulation of knowledge, community strength, and greater practical contributions - the arena I'll discuss next.

\section{THE APPRECIATION OF PRACTICALITY IN IS RESEARCH}

A third new championship I think we should enter is the appreciation of practical knowledge. I am using the word appreciation in the dual sense of growth (as in real estate appreciation) and of admiration (as in art appreciation). By practical research, I mean academic research that seeks primarily to describe, qualify or measure, evaluate or interpret practice in publications for academics. I am deliberately contrasting practical research with theoretical research, which seeks primarily to build or test academic theory, and with practitioner research, which addresses practitioners' concerns and is written for practitioners. Therefore, by appreciation of practical research, I mean that we as an academic field should (collectively) consume, reward, and contribute more heavily to a literature about what is going on in practice than we do today.

Several objections are undoubtedly forming in your minds. I'd like to dispel some of them, so that we can focus on the ones that really count. I am certainly not saying that all of our collective research output should be practical in nature. I recognize that academic theoretical work is fun and interesting in its own right, and it is important for academic legitimacy, among other reasons. I am merely saying that we should think of our collective research output as a portfolio and that we should expand the portion of our portfolio allocated to practical research.

I am also not saying that none of our work should be devoted to writing directly for practitioners and researching issues that addresses their concerns. This, too, is important work, and we probably don't do enough of it now. However, I am suggesting that we as academics should value, as a legitimate academic contribution, rigorous research that describes and evaluates what is going on in practice, even if that work makes no immediate attempt to build or test academic theory. I believe we should do this because it supports our educational mission and because it is useful for both theoretical research and research for practitioners.

\subsection{Educate Practitioners}

Many of us are educators in professional schools as well as being researchers. We have a collective responsibility to help our students apply in practice the theories and skills we teach them in the classroom. But many of us face considerable challenges in discharging this responsibility. One is the high rate of change in technology and 
practice that quickly renders textbooks and teaching materials obsolete. Historically, such materials have been one of the most important sources - other than personal experience and the trade press - of shared academic knowledge about the state of practice. I am personally quite concerned about the consequences of this rate of change in our field.

Let me give you a personal example from own work. When I started in this field, it was widely considered "best practice" to build information systems to fit an organization's existing business practices. We knew that lack of fit between systems and business practices gave rise to inefficiencies and resistance. However, it was also known that automating existing business processes that were inefficient or ineffective was not a good idea, since this approach often failed to produce the desired business benefits. Eventually, this insight crystallized with some ideas about what makes business processes good or bad and came to be known as "business process reengineering." The new best practice was to streamline business processes before system development. Or, perhaps I should say, the new best practice was to build new systems after the business processes had been carefully reengineered.

In the meantime, however, a generational shift had occurred from mainframe and midrange architectures to client-server computing. Many companies discovered that this was a competence-destroying shift; a number of large client-server projects failed at great expense. Simultaneously, software development firms began marketing integrated enterprise software packages ${ }^{6}$ in versions designed for the client-server architecture. The vendors claimed that these packages were very flexible - that is, capable of supporting a wide range of business processes - and that the packages incorporated the best practices in each functional area - that is, they were useful both after and before business process reeengineering. Many companies are now buying and installing these packages instead of developing their own client-server based administrative systems.

I recently studied three leading companies that had successfully installed such packages. As far as I can tell, their logic, which may well be today's best practice, can be summarized as follows:

Don't always reengineer business processes first. Instead, purchase and install a leading enterprise software package with no modifications (if at all possible), even if this means changing business practices. ${ }^{7}$ Chances are, you'll end up with a better business process than before because of built-in best practices, and you'll certainly have a more time and cost-

\section{${ }^{6}$ Examples include SAP's R/3, Peoplesoft, and BAAN software.}

${ }^{7}$ Installation of these packages involves filling in parameters in hundreds of tables but does not normally require writing or modifying software code. Modifying the code of an enterprise software package involves expense, delay, and risk; package vendors often refuse to provide ongoing support for packages that are modified by their purchasers. 
effective installation than with either custom development or package modification. If the process still isn't as good as you'd like, reengineer and change the package set-up, again without modifying it, so that you can continue to rely on vendor maintenance and enhancement.

In short, if you are old-timer like me and if you accept this summary as a statement of today's best practice in IS, you will certainly agree that best practice in our field has changed considerably from what it was twenty, or even five, years ago.

So, what's the problem here? The problem is the lag between this view of current best practice and that which you'll find in many current textbooks and teaching cases. In many intro courses, we're still in a mentality of building custom software for unique organizational needs while the world around us is demanding that we find ways to satisfy unique needs with generic software and components. As one of my experienced students recently exclaimed, "I've been in this field 25 years, and I've just realized that everything we do is 'one off.' But the vendors are approaching things in an entirely different manner."

The mentalities we help to shape can last a very long time - the entire careers of some of our students. But the generations of technology are much shorter (on the order of ten years) and may be shrinking. If our academic appreciation of practice doesn't change as fast as practice, we may be preparing our students for certain and rapid career extinction, particularly at times of major technical discontinuities. Peter Keen and other respected industry observers have estimated that only about half of IS professionals imbued with the mainframe mentality can make the mental shift to client-server computing. Are we still teaching important aspects of the mainframe mentality - like one off development? If so, how long will it be before we can present an up-to-date perspective on practice? Five years, perhaps? If so, that is about the time, technology analysts tell us, we can expect to see full-blown emergence of the next computing architecture. We'll again be out of synch.

Please understand me, here. I know that most of your departments offer courses in the latest architectural concepts and technologies. My worry is that our collective understanding of practice is not state-of-the-art and that our students may be suffering as a result. Qualitative IS researchers can exhibit great influence in turning this situation around.

\subsection{We Should Eat Our Own Dogfood}

A second reason I believe we need to produce and consume academically legitimate practical research involves professional values. Knowledge about practice must go into the advice we give practitioners, and it is also an important ingredient in sound theoretical development and testing. If we believe our practical knowledge is good enough for practitioners and for theoretical researchers, we ought to be willing to prove this by consuming it, writing it for, and reading it, ourselves. In Microsoft 
Corporation, this organizational value is known as "eating our own dogfood." I'll add that if eating one's own dogfood is good enough for Microsoft, it should be good enough for us.

When I first began preparing this talk, I thought I would be speaking more about doing research for a practitioner audience. This is something that I care a good deal about, as a result of my own historical experience, my research for the Advanced Practices Council of SIM International, and more recently my research for the Financial Executives Research Foundation. ${ }^{9}$ I have come to experience firsthand the great lack of credibility we academics have in the practitioner community. This credibility gap concerns me, because it affects our long-term economic well being and quality of work life as academics.

I asked myself how I would teach the skills of doing research for practitioners to doctoral students who lacked a strong background in practice or consulting. I reread two excellent books that I highly recommend, Usable Knowledge, by Lindblom and Cohen (1979), and Methods for Policy Research, by Ann Majchrak (1984). I realized what should have been obvious to me at the outset: to do good research that is intended to be useful to practitioners (as opposed to work that achieves the same result through serendipity), it is useful (if not essential) to think like a practitioner. For example, practitioners rarely get excited about theories that do not include variables that they can do something about. Ann Majchrzak calls these "malleable variables," and they are conspicuously absent from much academic IS research. Majchrzak explains that one of the first steps in good research for practice is learning how decisions related to the research topic get made, because this helps the researcher understand what kind of research results are likely to be used by practitioners.

So, my question then became "How would I teach IS doctoral students without significant practical or consulting experience to think like practitioners (as well as academics)?" This question produced the same sort of frustration I have felt when trying to teach IS or organizational behavior to students who entirely lack real-world business experience. I know that some of you excel at this, and I wish I knew how you do it.

It is clearly a challenge for us as academics to acquire and maintain both the academic and the practical mindsets, and it is even more challenging to teach them both effectively. I believe, however, that we need to try, and that developing the attitude of appreciation for practice would be a great start. In our culture, appreciation manifests itself in research activities, including writing, speaking, and reading

${ }^{8}$ In other words, Microsoft uses its own products whenever possible. Operating systems developers often work by "bootstrapping" - using the operating system under development as the development environment.

${ }^{9}$ The Advanced Practices Council is headed by Bob Zmud, who has written about the importance of research for practitioners in recent editorial statements in MIS Quarterly. 
related works. I believe that we as IS academics need a literature about practice written by and for us. I call this literature practical research. ${ }^{10}$

\subsection{What Is Good Practical Research?}

If you agree that practical IS research fills important needs, you may still need to be convinced that it is something that we qualitative IS researchers should include in our portfolio of activities. I hardly need to convince you that this is something we can do: with some shift in mindset, perhaps, our methods are ideally suited to practical research. Instead, I'll try to show why we need to do it, because it requires skills we have and because it is something that no other group of professionals has the skills and incentives to do.

I will define practical IS research as the "scientific observation" of IS practice that is documented in the public domain, where "scientific observation" is defined as "deliberate search, carried out with care and forethought, as contrasted with the casual and largely passive perceptions of everyday life." 11 Kaplan goes on to note that "It is the deliberateness and control of observation that is distinctive of science, not merely the use of special instruments" such as telescopes or social science datagathering devices. To these special instruments, I would add academic theory: the way in which we codify our understandings and communicate them to other scientists. Put differently, systematic observation of plants and animals is scientific, even in the absence of a theory to explain the observations. Similarly, research that systematically observes IS practice is a scientific contribution, even in the absence of explicit theory that predicts or explains the observations.

\section{Contrasts with Other Contributions}

Practical research is qualitatively different from other important contributions to knowledge made by academics and other professionals. However, it is superficially similar to some activities that we do not usually regard as academic or scientific. This similarity may cause some people to devalue practical research or fear that doing practical research would be disrespected. Fortunately, we qualitative IS researchers are trained to see through such distracting illusions. We of all people should see the uniqueness and importance of practical research.

Practical research differs from the development of teaching materials. Textbook and teaching case writers have different audiences and objectives than practical researchers. They write primarily for novices, rather than for people with substantial expertise; their goal is to convey basic concepts or to provide a shared context in

${ }^{10}$ Again, I contrast practical research with literature about practice for practitioners.

"Quote from Abraham Kaplan's "The Conduct of Inquiry," cited in Lindblom and Cohen 1979 , p. 16. 
which mutual discovery can occur. While researchers may obtain new insights from these words, their main research value accrues to their authors. By contrast, practical researchers write for other researchers. They generally omit details that novices need but experts know and include details that distract novices but interest experts.

Similarly, practical research differs from journalism. The genres of journalism can be loosely categorized as "news" - reportage of current events - and "features" detailed exploration or analysis of events or news makers. In general, journalists write for the public-at-large or for the modal member of a specialist audience, rather than for experts. In many cases, journalists are not experts in the topics they report, although they are often much better informed than their average reader. By contrast, practical researchers are experts writing for other experts. They judge themselves by standards of argumentation and evidence that are qualitatively different than those journalists use. In addition, practical researchers subject their work to review by peers, who control access to publication venues.

Practical research also differs from consulting and contract research. Most consultation and contract research is proprietary, meaning that the funders can restrict the publication and dissemination of knowledge. Funders may, for example, have the legal authority to block publication, censor certain details, impose publication delays, select publication venues, impose heavy charges for research reports, etc. Further, they, rather than researchers, may dictate key terms of the investigation. By contrast, practical researchers are committed to publishing their findings in the public domain. While research subjects and collaborators may exert some influence over the terms of investigation, practical researchers usually retain control over major research design decisions.

Theoretical research also differs from pedagogy, journalism, consulting, and contract research. What, then, are the essential differences between theoretical and practical research? Theoretical research is committed to the development and testing of academic theory - a particular knowledge form in which academics codify their understandings, explanations, and predictions in abstract terms and concepts. By contrast, practical research emphasizes disciplined empirical observations and ordinary knowledge ${ }^{12}$ about why things happen. Practical research honors concrete details, commonsense observations, and practitioners' rationales. It requires no immediate use of or contribution to abstract academic theory. On the other hand, practical research is not hostile or antithetical to theoretical research. Theoretical researchers will find practical research invaluable in theory development and in constructing sound tests of theory.

In other words, practical research is a qualitatively different type of academic contribution from theoretical research. Both are independently worthy of publication

\footnotetext{
${ }^{12}$ See Lindblom and Cohen (1979) for a good discussion of ordinary knowledge and its relationship to scientific knowledge.
} 
and other forms of appreciation in our community. We should not expect that every academician will excel at both.

\section{Examples of Practical Research Genres}

To make the contrasts between practical research and other important contributions clearer, I'll give a few examples of practical research genres that are, I believe, sorely needed in the rapidly changing IS field.

Revelatory cases. When is a single descriptive case study or small sample survey an important scientific contribution? According to case study expert Robert Yin (1994), revelatory cases can be invaluable to the scientific community when they involve unique, highly inaccessible, or leading-edge situations. Examples in IS include first-in-the-world (or biggest or best) IT applications, unusual business processes, and previously unexamined user behaviors or strategies for managing information technology. My personal favorite example of work in this genre is Tom Malone's study (1983) of the files and piles in people's workplaces. The expert academic reader of that paper in that historical era could instantly grasp the significance of the contribution made by Malone's disciplined observations and could put his ideas to use without further empirical or theoretical work by Malone.

Dissertation committee chairs may always require their students to demonstrate competence in theoretical research. Nevertheless, it is hard to credit arguments that would exclude insightful, disciplined observations like Malone's as publishable scientific contributions. Peer reviewers of work in this genre should have no trouble generating evaluation criteria that match the methodological rigor they demand to the scope of the author's claims or to the importance of the topic.

Comparisons. A second genre of practical research consists of comparative studies that identify similarities and differences in application features, process flows, or management policies and practices against important theoretical or practical criteria. For instance, I have heard it said that certain enterprise software packages are better suited to certain types of organizations or business processes than others. This strikes me as an important empirical question within the intellectual domain of our field. I'd like to read in our literature about how different types of enterprise packages actually handle different types of business processes and the potential and actual implications for their adopting organizations.

My personal favorite study in this genre is a working paper by Chris Kemerer and a colleague on the mortgage loan application systems developed by different financial organizations. The authors subsequently published a theoretical paper using their case data (Hess and Kemerer 1994), but I've long believed that the original, more descriptive, paper was itself worthy of note (e.g., of publication). Again, I believe that it is possible for us to establish high enough standards for the peer review of such comparative studies that we can appropriately appreciate them as academic contributions.

I might add here that the disciplined comparison of IT products and services is perhaps the major arena in which practitioners would welcome input from academics. 
Practitioners may well wonder whether the reports they read in trade publications have been influenced by advertising dollars. More important, they well may wonder how technical benchmarks interact or relate to important business criteria. It seems to me that IS academics, in general, and we qualitative IS researchers, in particular, are ideally positioned to make important contributions in this practical domain.

Evaluations. A third potentially important genre of practical research involves after-the-fact evaluations of various sorts: How usable was that software feature or package (and what can we learn from assessing it)? How effective was that application in various contexts? How effective were those implementation tactics or change processes? What impacts had that type of systems had?

We as qualitative IS researchers already know a great deal about usability, use, implementation, and impacts from a theoretical point of view. I' $m$ not saying that we know all we need to know theoretically and that we shouldn't strive to know more. However, I'll wager that we collectively know more about these topics theoretically than we do empirically and practically. And I feel this hampers me personally in my teaching and research. I love to read disciplined observations of these phenomena, and I am personally impatient when theoretical material demanded by reviewers pushes out useful empirical detail from an academic article. Rather than increasing page lengths, I like us to have fora for both practical and theoretical work and to treat well executed practical research as a legitimate scientific contribution.

Conceptual essays. A fourth potentially important genre involves disciplined assessments of practice in light of existing theory or known best practice. Why, for example, do "Microsoft Secrets" (Cusumano and Selby 1995) represent a significant departure from the traditional IS system development life cycle, and what does this mean, if anything, for IS teaching and research? What is different, if anything, about the ways in which the CSCW and IS communities view the world, and why should we care? Interpretive analyses may apply academic theory, but they may equally represent disciplined factual or pre-theoretical arguments about the important practical issues in our field.

\subsection{What Would it Take to Appreciate Practical Research}

Appreciation is never having to say you're sorry for "exploratory research." All research is exploratory, even research that seeks to confirm or disconfirm theory. No one study is conclusive, no matter what its findings or who finds them. Confirmation and disconfirmation of theory are matters of consensus among scientists. In the absence of consensus, all research is exploratory. And in this context, practical research is every bit as much a contribution to the scientific enterprise as is theory development and testing. The real questions for all research should be "Is it important and interesting?" and "Is it well done?"

Practical research should by no means be everything we as IS academics do. Again, I see this as a portfolio allocation decision, and just to start discussion, I'll suggest that practical research - that is, research about practice by and for academics - should 
be roughly $30 \%$ of our collective portfolio, and research for practitioners should be maybe another $30 \%$. Individuals will have portfolio allocation decisions, too, with some devoting $100 \%$ of their efforts to theoretical work, at least at certain stages of their careers. Others with different personal or institutional missions will allocate their efforts differently.

Clearly, my vision of appreciating practical research needs practical implementation steps. Most important in my view are publication outlets or tracks for practical research that we collectively value in assessing others' contributions. Appropriate criteria for peer evaluation of these works will emerge naturally once we have the joint commitment to them as important and interesting contributions to our science.

\section{CONCLUSIONS}

In this conceptual essay, I have argued that we played a great game yesterday. We won the major championship of academic acceptance. We should continue to play in this game and we should continue to play to win. However, because the big wins in academic acceptance are behind us, we have the opportunity now to find exciting new challenges and to develop new skills.

I have identified three important new arenas for us: celebration of our methodological diversity, convergence on our unique IS content, and appreciation for IS practice. Fundamentally, these three games all relate to one essential goal: respect for individual differences in talents and contributions. I hope that we qualitative IS researchers will enter all three games and play to win. The world needs us all and what we have to give.

\section{REFERENCES}

Cusumano, M. A., and Selby, R. A. (1995). “Microsoft Secrets: How the World's Most Powerful Software Company Creates Technology, Shapes Markets, and Manages People. New York: Free Press.

Griffith, T L., and Northcraft, G. (1994). "Distinguishing Between the Forest and the Trees: Media, Features, and Methodology in Electronic Communication Research.” Organization Science, Volume 5, Number 2 (May), pp. 272-285.

Grudin, J., and Palen, L. (1995). "Why Groupware Succeeds: Discretion or Mandate?” Proceedings of ECSCW '95. Dordrecht, The Netherlands: Kluwer, pp. 263-278.

Hess, C. M., and Kemerer, C. F. (1994). “Computerized Loan Origination Systems: An Industry Case Study of the Electronic Markets.” MIS Quarterly, Volume 18, Number 3 (September), pp. 251-275. 
Lindblom, C. E., and Cohen, D. K. (1979). Usable Knowledge: Social Science and Social Problem Solving. New Haven, Connecticut: Yale University Press.

Majchrzak, A. (1984). Methods for Policy Research. Thousand Oaks, California: Sage Publications.

Malone, T. W. (1983). "How Do People Organize Their Desks? Implications for the Design of Office Information Systems." ACM Transactions on Office Information Systems, Volume 1, Number 1 (January), pp. 99-112.

Miles, M. B., and Huberman, A. M. (1944). Qualitative Data Analysis: An Expanded Sourcebook, Second Edition. Newbury Park, California: Sage Publications.

Strauss, A., and Corbin, J. (1990). Basics of Qualitative Research: Grounded Theory Procedures and Techniques. Newbury Park, California: Sage Publications.

Van Maanen, J.; Dabbs, Jr., J. M.; and Faulkner, R. R. (1982). Varieties of Qualitative Research. Newbury Park, California: Sage Publications.

Yin, R. K. (1994). Case Study Research: Design and Methods, Second Edition. Newbury Park, California: Sage Publications.

\section{BIOGRAPHY}

M. Lynne Markus is Professor of Information Science and Management at the Peter F. Drucker Graduate Management Center, The Claremont Graduate School. Her research focuses on the role of information technology in organizational design, performance, and change. In 1996, she visited ISEG at the Universidade Technica de Lisboa, Portugal, as Fulbright/FLAD Chair in Information Systems. Dr. Markus has also taught at the School of Accountancy and Business, Nanyang Technological University, Singapore, the John E. Anderson Graduate School of Management at UCLA, and the Alfred P. Sloan School of Management at MIT and has consulted with Arthur D. Little, Inc. She holds a B.S. in Industrial Engineering from the University of Pittsburgh and a Ph.D. in Organizational Behavior from Case Western Reserve University. 